Submitted, accepted and published by:

Fuel Processing Technology 148 (2016) 188-197

\title{
On the attrition evaluation of oxygen carriers in
}

\section{Chemical Looping Combustion}

A. Cabello, P. Gayán*, F. García-Labiano, L. F. de Diego, A. Abad, J.

\section{Adánez}

Instituto de Carboquímica (ICB-CSIC), Department of Energy and Environment, Miguel Luesma Castán 4, Zaragoza 50018, SPAIN.

* Corresponding author. Tel.: +34 976733 977. Fax: +34 976733 318. E-mail address: pgayan@icb.csic.es (Pilar Gayán) 


\title{
On the attrition evaluation of oxygen carriers in
}

\section{Chemical Looping Combustion}

\author{
A. Cabello, P. Gayán*, F. García-Labiano, L. F. de Diego, A. Abad, J.
}

\section{Adánez}

Instituto de Carboquímica (ICB-CSIC), Department of Energy and Environment, Miguel Luesma Castán 4, Zaragoza 50018, SPAIN.

\footnotetext{
* Corresponding author. Tel.: +34 976733 977. Fax: +34 976733 318. E-mail address: pgayan@icb.csic.es (Pilar Gayán)
}

\begin{abstract}
Chemical Looping Combustion (CLC) is one of the most promising processes for the low-cost capture of $\mathrm{CO}_{2}$. It is based on the transfer of oxygen from air to the fuel by means of a solid oxygen carrier that circulates between two interconnected fluidized bed reactors: the fuel reactor and the air reactor. $\mathrm{CO}_{2}$ capture is inherent to this process since air does not become mixed with the fuel. A key issue for the large-scale development of CLC technology is the selection of oxygen carrier materials with suitable properties such as high reactivity and good fluidization. Another important feature that an oxygen carrier must fulfil is to have high resistance to attrition. For this purpose, several particle characteristics related to attrition resistance were analysed in this work on 23 oxygen carriers, both natural and synthetic, prepared by different methods and using different metal oxides. Particle crushing strength and Air Jet Index (AJI) were determined for the fresh materials, as well as the attrition rate and the corresponding particle lifetime during multi-cycle redox reactions in a continuously operated CLC unit for
\end{abstract}


gaseous fuels. A comparison was made of the different methods used to evaluate attrition behaviour.

The AJI-ASTM test for particles subjected to long-term CLC operation was used as a standard screening tool to evaluate the attrition behaviour of the oxygen carriers. Finally, a methodology was proposed for the selection of oxygen carriers as eligible materials for CLC scale-up based on attrition behaviour.

Keywords. Attrition, oxygen carrier, Chemical Looping Combustion, $\mathrm{CO}_{2}$ capture.

\section{Introduction}

Fossil fuels are expected to maintain their relevant role in the near future. Therefore, the development of $\mathrm{CO}_{2}$ Capture and Storage (CCS) technologies is essential for the production of clean energy from fossil fuel combustion and to reduce global $\mathrm{CO}_{2}$ emissions $[1,2]$. Great efforts have been made in recent years to develop new low-cost CCS technologies. Among them, the Chemical-Looping Combustion (CLC) process is considered to be among the best alternatives for reducing the cost of $\mathrm{CO}_{2}$ capture [3]. In the CLC process, the oxygen for combustion is supplied to the fuel by means of an oxygen carrier, mainly in the form of a metal oxide, which circulates between two interconnected reactors, the fuel and air reactors. In the fuel reactor, the fuel is oxidized to $\mathrm{CO}_{2}$ and $\mathrm{H}_{2} \mathrm{O}$ by the metal oxide $\left(\mathrm{Me}_{\mathrm{x}} \mathrm{O}_{\mathrm{y}}\right)$, which in turn is reduced to $\mathrm{Me}_{\mathrm{x}} \mathrm{O}_{\mathrm{y}-1}$. The gas produced in this first step contains primarily $\mathrm{CO}_{2}$ and $\mathrm{H}_{2} \mathrm{O}$. After steam condensation and purification, a highly concentrated stream of $\mathrm{CO}_{2}$ is achieved that is ready for transport and storage. The reduced metal oxide is oxidized with air in the air reactor, and the regenerated material is then ready to start a new cycle. The flue gas obtained in this second step contains $\mathrm{N}_{2}$ and unreacted $\mathrm{O}_{2}$. The net chemical reaction over the two steps, and therefore the total heat evolved in the CLC process, is the same as in conventional combustion where the fuel is burned in direct contact with the oxygen present in the air stream. However, the oxygen depleted air and $\mathrm{CO}_{2}$ are obtained in separated gaseous streams. In this regard, CLC is a combustion process with inherent $\mathrm{CO}_{2}$ separation, i.e. avoiding the need for $\mathrm{CO}_{2}$ separation 
units, an energy penalty for gas separation. This concept is the main advantage of the process in comparison with other $\mathrm{CO}_{2}$ capture technologies.

Most of the CLC plants currently in existence worldwide use the configuration of two interconnected fluidized-bed reactors [4], one of them being the fuel reactor and the other the air reactor. In addition, two loop-seal vessels are used in order to avoid gas leakage between the reactors.

A key issue in the system performance is the oxygen carrier material. This material must fulfil a number of characteristics in order to be considered as a suitable oxygen carrier for CLC: sufficient oxygen transport capacity; favourable thermodynamics for fuel conversion to $\mathrm{CO}_{2}$ and $\mathrm{H}_{2} \mathrm{O}$; high reactivity for reduction and oxidation reactions, in order to reduce the solids inventory in the reactors; negligible carbon deposition to prevent the release of $\mathrm{CO}_{2}$ in the air reactor, which would reduce $\mathrm{CO}_{2}$ capture efficiency; good fluidization properties (low tendency to agglomerate); resistance to attrition, in order to minimize losses resulting from elutriated solids; limited cost; and environmental friendly behaviour. The first characteristic is intrinsically dependent on the redox system. In this regard, metal oxides based on $\mathrm{Ni}, \mathrm{Cu}, \mathrm{Fe}$ and Mn have been widely used [4]. Cost and the environmental characteristics depend on the type of metal oxide used. The quality of the other required characteristics must be experimentally determined for each specific material. The method used in the preparation of the materials strongly affects the properties of the oxygen carriers. The distribution of the metal oxide on the inert material used as support, and the possible interaction between them can affect the oxygen carrier reactivity and stability during consecutive redox cycles. There are different methods of preparation, in which powders of metal oxide and support are mixed, namely mechanical mixing and extrusion, freeze granulation, spray-drying, and spin flash. In other methods, the solid compounds are generated by precipitation, e.g. co-precipitation, dissolution, sol-gel, and solution combustion. Moreover, in the impregnation method, a solution containing the active metal is deposited on a resistant and porous solid support. At present, the preparation methods planned for the large-scale production of oxygen carriers are spray-drying and impregnation [4]. Natural ores and by-products from industrial processes have also been 
proposed as oxygen carriers and are now considered to be of great interest, particularly for solid fuels $[4,5]$.

Based on the work carried out over the last decade, a relevant number of materials have shown high reactivity and avoidance of both carbon deposition and agglomeration during its use in CLC units. However, the number of materials with high strength and low attrition values is lower. Specific studies on oxygen carrier attrition are limited, despite the attrition behaviour of particles being an important characteristic for their use in fluidized bed reactors. Attrition is influenced by bed material properties, reactor geometry, operating conditions and occurrence of chemical reactions. Scala et al. [6] described the main types of mechanical attrition patterns to which particles are subjected in fluidized bed combustors, indicating the typical particle size distribution (PSD) curves resulting after each type of attrition. These patterns are abrasion, chipping, disintegration and splitting or fragmentation. Depending on the velocity of collision between the particles, the mode of attrition varies from surface abrasion to fragmentation [7]. Surface abrasion occurs when particles are subjected to friction or collisions at low velocity. This phenomenon mainly takes place in the dense region of fluidized beds and involves the generation of very fine particles due to the wearing of surface asperities. In this case, the PSD of the material tested in the fluidized bed reactors is practically unaltered with respect to mother particles. Fragmentation of particles occurs when the collisional energy is very high. Mechanical fragmentation occurs in the region of fluidizing gas jets. High velocities at the inlet of cyclones are normally avoided in order to maintain the cyclone pressure drop at a reasonable level. Moreover, temperature gradients and chemical reactions of the particulate material may generate stresses that lead particles to fracture [7].

Attrition influences two important aspects of fluid bed operation, namely particle elutriation and PSD. Elutriation of fine particles out of the system, mainly caused by the surface abrasion mechanism, may lead to the loss of bed material from the reactors. On the other hand, a significant change in the PSD of the bed material due to fragmentation affects the operation of the fluidized bed unit. In fact, bed fluid-dynamics, heat and mass transfer coefficients, and heterogeneous reaction rates depend on the PSD of the bed material [8]. 
In spite of the relevance of the particle attrition, which is a critical parameter for the upscaling of CLC technology for gaseous fuels, the determination of this parameter for oxygen carriers has received little attention in the CLC community. Different methods can be used to evaluate the attrition resistance of oxygen carriers.

During the initial years of CLC technology development, crushing strength was the most used method. In principle, the higher the crushing strength value, the greater the stress that the oxygen carrier particles could withstand in continuous motion within two interconnected fluidized beds and, therefore, the less attrition there would be. However, the results were not definitive in many cases. As an example, Rydén et al. [9] found that many materials exhibited a poor correlation between their attrition behaviour in continuous CLC units and their corresponding crushing strength values.

Another option is to determine the attrition rate and the corresponding particle lifetime during CLC operation with gaseous fuels, both in batch and continuous CLC systems. In order to determine attrition rate and particle lifetime accurately, it is necessary to operate continuous CLC units over long periods of time. In this regard, there is currently little information available concerning long-term operation with oxygen carriers [10-14] and industrial data is not yet available. The lifetime of an oxygen carrier can be defined as the mean time that the particles of this material are under reaction (reduction and oxidation) in the system without suffering the attrition and/or fragmentation processes that produce particle elutriation out of the system. Oxygen carrier particles with a size lower than $45 \mu \mathrm{m}$ are considered as fines generated by attrition in CLC [15]. It is assumed that particles of this size have a short residence time in a commercial unit, and thus are of little use in the process. The cost of the makeup stream of solids to replace the loss of fines depends on particle lifetime and the cost of the oxygen carrier. The cost of an oxygen carrier will be the sum of several factors, including the cost of the metal oxide and the inert material, and the manufacturing cost. When industrial methods are used, the manufacturing cost is quite low and the final cost is mainly given by the price of the raw materials. Abad et al. [16] presented an evaluation of the cost of the makeup flow of oxygen carriers per tonne of $\mathrm{CO}_{2}$ avoided based on different characteristics of the studied materials, and 
corroborated that the total cost of the oxygen carrier in the CLC process greatly depended on the lifetime of the particles. Therefore, a longer oxygen carrier lifetime is preferred in order to keep the cost low.

Furthermore, attrition resistance has been also evaluated using customized attrition rigs $[9,17-$ 18]. In these studies, the researchers developed their own devices and attrition indexes, which makes it very difficult to extrapolate and compare the obtained results. However, in industrial practice, a standard ASTM method exists for catalysts used in the Fluid Catalytic Cracking process (FCC). In the FCC process, particles circulate between two interconnected fluidized bed reactors in a similar way to in the CLC process. The ASTM standard D5757 [19] was primarily designed for catalysts; however, the objective of this work was also to evaluate whether this standard would be suitable to provide reliable information regarding the attrition behaviour of oxygen carriers for the scale-up of the CLC process with gaseous fuels. Moreover, several particle characteristics related to attrition resistance were also analysed for different oxygen carriers, both natural and synthetic, prepared by different methods and using different metal oxides. In this regard, the crushing strength and attrition rates obtained during multi-cycle redox reactions at high temperature in a continuous CLC unit were also determined. Additionally, a comparison was also made between the three evaluated parameters, i.e., Air Jet Index (AJI) according to ASTM standard D5757, crushing strength, and attrition rate measured in a continuous CLC system.

\section{Experimental section}

\subsection{Oxygen carrier materials}

In this work, 23 different oxygen carriers were evaluated. These materials were based on manganese, nickel, copper and iron. Most of them were prepared by the incipient impregnation method, except the Mn-based oxygen-carriers, which were prepared by spray-drying, and a natural Fe-based ore. Different supports were used for the oxygen carriers prepared by the impregnation method, such as $\gamma-\mathrm{Al}_{2} \mathrm{O}_{3}$ and $\alpha-\mathrm{Al}_{2} \mathrm{O}_{3}$ from several commercial suppliers, $\mathrm{CaAl}_{2} \mathrm{O}_{4}, \mathrm{MgAl}_{2} \mathrm{O}_{4}$ and $\mathrm{ZrO}_{2}$. The particle size of the Ni- and Fe-based oxygen carriers ranged between $100 \mu \mathrm{m}$ and $300 \mu \mathrm{m}$, whereas particles in the size ranges 90-200 $\mu \mathrm{m}$ and 100-500 $\mu \mathrm{m}$ 
were used for the Mn-based and Cu-based oxygen-carriers, respectively. These differences in oxygen carrier particle size were mainly due to the different density values and preparation methods used.

\subsection{Oxygen carrier characterization}

Mechanical strength, i.e. crushing strength in Newtons, was measured using a Shimpo FGN-5X apparatus. This parameter was obtained as the average value of at least 20 measurements. Attrition resistance was determined using a three-hole air jet attrition tester ATTRI-AS (Ma.Tec. Materials Technologies Snc) configured according to the ASTM-D-5757 standard [19]. As specified in the ASTM method, $50 \mathrm{~g}$ of material was tested under an air flow of 10 $1 / \mathrm{min}$, which was equivalent to a jet speed of $490 \mathrm{~m} / \mathrm{s}$. The weight loss of fines was recorded after $1 \mathrm{~h}$ and $5 \mathrm{~h}$ of operation, respectively. The percentage of fines after a $5 \mathrm{~h}$ test is defined as AJI, see equation (1):

$$
\mathrm{AJI}=\frac{\mathrm{m}_{5 \mathrm{~h}}}{\mathrm{~m}_{\mathrm{s}}} \cdot 100
$$

where:

$m_{5 h}=$ mass of the fines collected from the attrition test assembly at $5 \mathrm{~h}$.

$m_{s}=$ mass of the sample loaded into the apparatus (nominally $50 \mathrm{~g}$ ).

According to the ASTM method, particles with a size lower than $20 \mu \mathrm{m}$ are considered as fines. AJI values were determined in duplicate both for fresh and used samples subjected to redox cycles at high temperature in a continuous CLC unit. Moreover, the particle size distribution of the samples was analysed via a laser diffraction technique, according to the ISO13320 standard, with a LS13320 Beckman Coulter apparatus.

\subsection{W continuous CLC system}

The combustion and attrition behaviours of most of the oxygen carriers selected for this work were analysed in a continuous CLC pilot plant $\left(500 \mathrm{~W}_{\text {th }}\right)$ using gaseous fuels, see Figure 1 . This bench-scale CLC unit consists of two bubbling fluidized-bed reactors, the fuel reactor and the air reactor, interconnected by a loop seal, a riser for solids transport, a cyclone, and a solids valve to control the circulation rate of the oxygen carrier, which can be measured by means of a 
diverting solids valve. Furthermore, this facility has two small deposits to take samples from both reactors to carry out subsequent analyses, and two filters, which collect fines elutriated during the continuous CLC process. This unit was described in detail in a previous work [10]. Different gases such as $\mathrm{CH}_{4}, \mathrm{CO}, \mathrm{H}_{2}$, syngas, light hydrocarbons $\left(\mathrm{C}_{2}-\mathrm{C}_{3}\right)$ and PSA-off gas were used as fuels. These gases were fed through a perforated plate distributor. More than 1000 hours of continuous operation were carried out with different oxygen carriers. Table 1 summarizes the main operating conditions used during the tests performed in the continuous CLC unit.

Full conversion of fuels was achieved with most oxygen carriers analysed at specific operating conditions, with the exception of the Ni-based materials, owing to thermodynamic restrictions, and the natural $\mathrm{Fe}$-based material, which presented a poor $\mathrm{CH}_{4}$ conversion.

The experimental attrition rate as a function of the operating time was determined by collecting and weighing elutriated particles from the reactors. The particles collected in the filters with a size higher than $45 \mu \mathrm{m}$ were returned to the system. Thus, the attrition rate, A (wt- $\% / \mathrm{h}$ ), is defined through the following equation:

$$
\text { Attrition }=\mathrm{A}(\mathrm{wt}-\% / \mathrm{h})=\frac{\mathrm{m}_{\mathrm{f}}}{\mathrm{m}_{\mathrm{t}} \cdot \Delta \mathrm{t}} \cdot 3600 \cdot 100
$$

where $m_{f}$ is the weight of elutriated particles with a particle size lower than $45 \mu \mathrm{m}$ for a particular period of time, $\Delta \mathrm{t}$ (expressed in seconds), which is typically $300-480$ minutes, and $m_{t}$ is the total weight of solids inventory in the CLC plant.

Usually, the attrition rates measured were relatively high during the first hours of operation due to rounding effects, but progressively approached a constant value for many materials. These stabilized values were taken to estimate the particle lifetime. The particle lifetime of an oxygen carrier can be estimated from the attrition rate through the following equation:

$$
\text { Particle lifetime }(h)=\frac{100}{A}
$$

However, there are other materials for which the attrition rate starts to increase after a certain period of operation in the CLC plant. In these cases, the operation must be stopped, and the 
particle lifetime is calculated with the last attrition value measured. Note that the real particle lifetime of the material will be lower than the estimated particle lifetime.

As an example, Figure 2 shows the attrition rate profiles of the $\mathrm{Cu}_{-} 4$ oxygen carrier (see Table 2) tested in the $500 \mathrm{~W}$ continuous CLC system at two different temperatures, i.e. $800^{\circ} \mathrm{C}$ and $900^{\circ} \mathrm{C}$. As can be observed, the amount of fines collected in the filters of the CLC unit was very high during the first hours of operation in both cases. However, the attrition behaviour of this material clearly changed for longer times of operation depending on the temperature.

\section{Results}

The main results obtained in this work are summarized in Table 2. This table shows the mechanical strength and AJI results for fresh samples of the evaluated oxygen carriers. Some of these materials were also tested in the continuous CLC facility at high temperature. The experimental conditions used in each case, together with the stabilized attrition rate and the corresponding particle lifetime values, are also shown in this table. With regard to the test conditions, it should be pointed out that the temperature values refer to the operating temperature used in the fuel reactor of the continuous CLC unit. Moreover, results of both AJI and crushing strength tests for samples used during long-term continuous CLC tests are presented.

In Table 2, the different materials analysed in this work are divided into four groups based on the active metal oxide of the oxygen carrier. The reference used to designate the oxygen carrier along with the weight content of metal oxide present in the material, the inert compound used as support and the method of preparation can be also found in this table. For example, the Ni_2 material refers to an oxygen carrier with $11 \mathrm{wt} . \% \mathrm{NiO}$ prepared by impregnation on $\mathrm{CaAl}_{2} \mathrm{O}_{4}$. Most of oxygen carriers were prepared through impregnation. Nevertheless, the list of materials tested in this work is completed with two Mn-based oxygen carriers prepared by spray-drying, where the whole oxygen carrier is considered to be an active material for the CLC process, and with an iron ore, whose iron oxide weight content was $76 \%$. 
Firstly, a comparison between mechanical strength and AJI values for fresh materials is shown in Figure 3. It should be pointed out that the generally accepted threshold values of both parameters for the CLC process are marked in the Figure, i.e. $1 \mathrm{~N}$ and $5 \%$, respectively. In the case of the crushing strength parameter, previous literature reported that values under $1 \mathrm{~N}$ might be too soft to carry out a long-term circulation process in fluidized beds at optimum conditions [29]. In relation to AJI, it should be noted that in the catalyst industry, materials with an AJI of $5 \%$ or below are considered suitable for their use in a transport reactor [30]. The accepted value of $1 \mathrm{~N}$ for the crushing strength parameter is valid for oxygen carriers with a particle size in the range used in this work $(90-500 \mu \mathrm{m})$. In the case of the AJI-ASTM tests, the accepted value of $5 \%$ is suitable for particle sizes that range from $10 \mu \mathrm{m}$ to $180 \mu \mathrm{m}$. In this regard, it should be taken into consideration that variation in the particle size has an effect on crushing strength since this parameter usually increases for oxygen carrier materials with higher particle sizes. However, the effect of particle size on AJI was also analysed for different oxygen carriers and it was found that a variation in size hardly affected attrition. Five of the materials used in this work $\left(\mathrm{Mn} \_1, \mathrm{Ni} \_1, \mathrm{Cu} \_3 \mathrm{a}, \mathrm{Fe} \_1\right.$ and $\left.\mathrm{Fe} \_2\right)$ were subjected to AJI-ASTM tests at two different particle size ranges: $10-180 \mu \mathrm{m}$ and 100-300 $\mu \mathrm{m}$. In all cases, the deviation of the AJI value for the $100-300 \mu \mathrm{m}$ range was lower than $\pm 10 \%$ with respect to the obtained value for the $10-180$ $\mu \mathrm{m}$ range established in the ASTM D5757 standard.

Figure 3 shows the poor correlation observed between crushing strength and AJI for fresh particles. Fresh particles with high crushing strength usually showed low attrition values during AJI measurements. However, a high variation in AJI results was found for oxygen carrier particles with low crushing strength values.

Crushing strength and AJI were also correlated with the particle lifetime estimated during continuous CLC tests, see Figures 4 and 5. A particle lifetime of 2000 hours seems to be a suitable cut-off value for oxygen carriers. Extrapolating this value to a large-scale CLC unit, it would be necessary to renew the whole solids inventory between three and four times per year, which is a usual rate of renewal for the FCC process. From these figures, it can be observed that 
there was no correlation between the studied parameters, since low particle lifetimes $(<1000 \mathrm{~h})$ were found throughout the entire range of crushing strength and AJI values.

In the case of the $\mathrm{Cu}$-based oxygen-carriers, other variables, such the operating temperature and the support used, had an important effect on particle lifetime in the CLC unit. The variation in the operating temperature in the fuel and air reactors caused a great change in the attrition rate profile of $\mathrm{Cu}$-based oxygen carriers. For example, $\mathrm{Cu}$ _4a material, which is a $\mathrm{Cu}$-based oxygen carrier with an active copper oxide content of $14 \mathrm{wt} . \%$ prepared by the impregnation method using $\gamma-\mathrm{Al}_{2} \mathrm{O}_{3}$ as support, was tested in the continuous CLC facility at a temperature of $800^{\circ} \mathrm{C}$, in both the fuel and air reactors. The attrition behaviour of this material at these conditions was excellent, achieving a stabilized particle lifetime of 5000 hours. The corresponding attrition rate profile is shown in Figure 2. However, this oxygen carrier was also tested in the same CLC unit at a temperature of $900^{\circ} \mathrm{C}$ in both reactors. In this case, the oxygen carrier was designated as $\mathrm{Cu}$ 4b in Table 2. The result was completely different since the increase in temperature of the CLC system caused a dramatic change in the attrition rate profile in terms of an abrupt increase of fines generation after 50 hours, which led to a substantial reduction in the estimated particle lifetime, as can be observed in Figure 2.

The use of different compounds as supports also had an effect on the attrition behaviour of the impregnated $\mathrm{Cu}$-based oxygen carriers in the continuous $\mathrm{CLC}$ unit. In particular, $\mathrm{Cu} \_2, \mathrm{Cu} 5$ and $\mathrm{Cu} \_6$ oxygen carriers used $\alpha-\mathrm{Al}_{2} \mathrm{O}_{3}, \gamma-\mathrm{Al}_{2} \mathrm{O}_{3}$ with $\mathrm{NiO}$, and $\mathrm{MgAl}_{2} \mathrm{O}_{4}$ as support materials, respectively. These three materials were subjected to long-term experimental campaigns in the continuous CLC unit at a temperature of $900^{\circ} \mathrm{C}$ in both the fuel and air reactors, and a significant difference in attrition performance was observed [25]. The $\mathrm{Cu} 5$ oxygen carrier was the material that achieved a reasonable particle lifetime in the $500 \mathrm{~W}$ continuous CLC system, i.e. 2700 h. Furthermore, it must be highlighted that both crushing strength and AJI of the fresh samples of $\mathrm{Cu}_{-} 2, \mathrm{Cu}{ }_{-} 5$ and $\mathrm{Cu}_{-} 6$ materials clearly fulfil the accepted values for both parameters, see Figure 3. This result revealed the great relevance of the support selected when impregnated materials are considered for use. 
With regard to the Fe-based oxygen carriers, it can be stated that the materials prepared by the method of impregnation generally had lower crushing strength values than the Cu-based materials using the same supports. Low particle lifetime values were usually obtained. In this case, it was not possible to find a definite conclusion regarding the relation between the AJI parameter and the estimated particle lifetime since several Fe-based materials with low AJI values did not present reasonable particle lifetimes. Moreover, the Fe-based oxygen carriers prepared by impregnation on alumina from several suppliers (cf. Table 2, Fe_1 to Fe_11 materials) presented high dispersion in crushing strength, AJI and particle lifetime. These results corroborated the importance of selecting a support with good physicochemical properties when impregnated materials are considered.

Based on the results shown in Figures 3-5, it can be stated that, on the one hand, a high AJI for a fresh oxygen carrier implies that the material performs poorly in a continuous CLC unit in terms of attrition resistance. On the other hand, an oxygen carrier that has a low AJI value does not guarantee good behaviour in a continuous CLC unit in terms of attrition resistance. Therefore, the AJI-ASTM test method for fresh oxygen carrier particles cannot be proposed as a suitable method to predict the mechanical behaviour in a small-scale CLC process. These results were expected since the thermal and chemical stresses that the particles suffer during CLC operation can greatly affect its mechanical behaviour. However, neither the AJI-ASTM test method nor measuring the crushing strength take these stresses into account [6]. Brown et al. [18] reported a similar conclusion as they found that attrition was strongly influenced by repeated cycling and thus testing fresh materials was not suitable for predicting the attrition behaviour of oxygen carriers under real CLC operating conditions. Nevertheless, materials with an AJI value lower than $5 \%$ and a crushing strength higher than $1 \mathrm{~N}$ could be selected during an initial screening. The change in the mechanical resistance of some materials due to the thermal and chemical stresses they underwent during CLC operation was clearly observed in the evolution of the AJI value with operating time. A clear example was the Fe_6 material, whose AJI changed from 2\% for fresh particles to $41 \%$ for particles after 50 hours of operation, see Figure 6 (a). Another oxygen carrier that showed a similar behaviour was the $\mathrm{Cu}_{-} 4 \mathrm{~b}$ material. In this case, AJI 
increased from $3 \%$ to $46 \%$ after 65 hours of continuous operation. Nevertheless, other materials, such as the $\mathrm{Cu}_{-} 4 \mathrm{a}$ oxygen carrier, kept their AJI values roughly constant throughout the time of operation in the continuous CLC unit. It is interesting to note that the estimated particle lifetime for the $\mathrm{Cu}$ _4a oxygen carrier was $5000 \mathrm{~h}$ and thus well above the recommended cut-off value of 2000 h. Figure 6 (b) shows the attrition rate profiles obtained in the CLC unit for the three evaluated oxygen carriers. For the $\mathrm{Fe} \_6$ and $\mathrm{Cu}_{-} 4 \mathrm{~b}$ materials, AJI clearly increased with the time of operation, whereas the evolution of the attrition rate at continuous CLC conditions behaved differently. The attrition rate of the Fe_6 material stabilized at a moderate value of $0.09 \% / \mathrm{h}$, corresponding to a particle lifetime of 1125 hours, while the $\mathrm{Cu}_{-} 4 \mathrm{~b}\left(900^{\circ} \mathrm{C}\right)$ underwent an abrupt increase in generated fines, which led to a very low particle lifetime value. The appearance of these two different behaviours in relation to the experimental attrition found during continuous CLC operation might indicate that when AJI increases significantly with the time of operation, the oxygen carrier will eventually fail, which can be seen by a dramatic increase in the attrition rate. However, a problem arises because there is an uncertainty as to the suitable moment to stop experimentation. It is concluded that it is not necessary to continue operation since a continuous and significant rise in AJI indicates a high level of degradation, which will mean the destruction of the oxygen carrier. On other hand, materials such as the $\mathrm{Cu}$ 4b oxygen carrier, which throughout the time of operation present a constant and low AJI as well as an attrition rate well below the threshold value in a continuous CLC unit, can be relied upon to show good, long-term performance in terms of attrition resistance.

Figure 7 shows a comparison between AJI for fresh and used particles. It should be pointed out in this case that the used oxygen carrier particles refer to samples extracted from the CLC unit at the end of each experimental campaign, see "Time of operation" column in Table 2. As can be observed, this parameter increases to a great extent for most of the materials from the fresh to the used state. This is evidence of the relevance of thermal and chemical stresses for oxygen carriers subjected to long-term CLC tests. However, there were other materials whose AJI values were kept roughly constant throughout the time of operation, and the corresponding experimental attrition rates followed the profile showed by $\mathrm{Cu}_{-} 4 \mathrm{a}$ material in Figure 6 (a). 
The tendency of oxygen carrier particles towards fragmentation as the result of thermal and chemical stresses can be evaluated by means of the PSD technique. Furthermore, this technique provides relevant information regarding the predominant attrition mode of the oxygen carrier particles during both continuous operation in a CLC unit and AJI attrition measurements.

As an example, Figure 8 shows the change in the PSD of three oxygen carriers tested in this work that show very different behaviours with regard to attrition performance. The materials shown in Figure 8 are Fe_3, Fe_6 and Ni_1. For each oxygen carrier, four different samples were analysed, namely (1) fresh sample, (2) sample obtained after an AJI-ASTM test carried out with fresh particles, (3) used sample extracted from the air reactor of the continuous CLC unit at the end of the experimental campaign, and (4) sample obtained after an AJI-ASTM test carried out with used particles from the continuous CLC unit.

The fresh particles of the $\mathrm{Fe} 3$ oxygen carrier did not show suitable properties regarding attrition behaviour, given that the crushing strength and AJI were $0.5 \mathrm{~N}$ and $40 \%$, respectively. This material was tested in the continuous CLC facility over 52 hours of operation, and the stabilized attrition rate was very high, i.e. $0.32 \% / \mathrm{h}$, which corresponded to an estimated particle lifetime of 320 hours. Figure 8 (a) shows that despite the high attrition rate of this material in the CLC unit, the mode of attrition was abrasion since the PSD of the used particles hardly differed from that of the fresh particles. However, the PSD of the used particles after the AJIASTM test revealed that the mode of attrition had changed significantly to a mixed-mode between fragmentation and disintegration, according to the particle breakage patterns presented by Scala et al. [6]. A slight tendency to disintegration was also observed for the fresh particles after the AJI-ASTM test. This result was expected since the failure pattern designated as disintegration is typically displayed in soft materials such as the $\mathrm{Fe} \_3$ oxygen carrier.

Regarding the Fe_6 material, it can be observed that the fresh particles presented much better properties than those shown by the Fe_3 material. In this case, the crushing strength was higher $(1.0 \mathrm{~N})$ and the AJI value was lower $(2.3 \%)$. The corresponding PSD profile after the AJIASTM test revealed the absence of disintegration or fragmentation, see Figure 8 (b). However, as observed in Figure 6, AJI increased dramatically during operation in the continuous CLC 
unit, indicating that the thermal and chemical stresses to which the material was subjected during CLC operation caused a great change in its mechanical resistance. These thermal and chemical stresses also intensified the tendency of the used oxygen carrier particles towards fragmentation, as can be clearly observed in Figure 8 (b).

Finally, fresh particles of the Ni_1 oxygen carrier showed excellent properties in terms of attrition behaviour, see Table 2. Furthermore, this material was tested in the continuous CLC facility for 100 hours of operation and its particle lifetime was estimated to be 10000 hours, which is the highest value given for a material tested in this work. The AJI value of the particles after 100 hours of operation was $4.1 \%$, a value even lower that of the fresh material. In this case, not only was AJI constant despite the high temperatures and reactions that occurred during operation in the CLC unit, but also the PSD of the used sample after an AJI-ASTM test was unaltered with respect to fresh particles, see Figure 8 (c).

A comparison between the AJI values obtained for the used oxygen carriers and the corresponding particle lifetime values estimated in the continuous CLC unit is presented in Figure 9. Here, the lowest values of the AJI-ASTM test for used particles $(<5 \%)$ are related to the highest particle lifetimes determined in the CLC unit, whereas the materials with high AJI values have poor attrition performance in the continuous CLC unit. These findings again corroborated that the mechanical resistance of the oxygen carriers changed not only due to physical attrition effects, but also due to thermal and chemical stresses experienced during CLC operation. From these results, it can be concluded that the AJI-ASTM test for particles subjected to long-term CLC operation can be used as a standard screening tool to foresee the attrition behaviour of oxygen carriers, while providing an indication of their potential use at an industrial scale.

\section{Discussion}

The final decision as to the suitability of a material as an oxygen carrier for the CLC process is a combination of reactivity, attrition resistance and cost. In relation to the economic analysis of an oxygen carrier, Abad et al. [16] concluded that despite the cost of the oxygen carrier particles 
being a relevant factor to take into account, it does not represent a limitation to the development of CLC technology as a very promising option for $\mathrm{CO}_{2}$ capture if oxygen carriers with sufficient reactivity and high attrition resistance are produced. In addition, this reactivity should not deteriorate with time of operation and the succession of redox cycles. Usually, these factors are evaluated in the initial steps during the development of an oxygen carrier, and therefore are not considered here in the discussion regarding the evaluation of a specific material.

In this work, a detailed analysis of several particle characteristics related to attrition resistance was performed on 23 different oxygen carriers and, as a conclusion of this research, a methodology has been suggested for the selection of oxygen carriers as eligible materials for CLC scale-up based on their attrition behaviour. A scheme of the proposed methodology is presented in Figure 10. Firstly, a fresh sample of an oxygen carrier is subjected to a crushing strength test. If crushing strength is higher than $1 \mathrm{~N}$, this fresh material is then subjected to an AJI-ASTM test. In the case where the crushing strength of the oxygen carrier is below $1 \mathrm{~N}$, the material should be modified (support, method of preparation, calcination conditions, etc.) to improve this factor. Nevertheless, particles with a crushing strength value lower than $1 \mathrm{~N}$ could be selected for the following test, but it must be taken into account that there will be a high risk of particle integrity failure [9].

In the next step, if the AJI value is lower than $5 \%$, the oxygen carrier is then evaluated in a continuous CLC plant until its attrition rate is stable. During this process, oxygen carrier particles are extracted from the CLC unit at regular intervals and the AJI measurement is repeated. In order for the attrition values obtained in the CLC unit to be considered reliable, the AJI measurement should show a stable value. In addition, if the resulting values are again lower than $5 \%$, the oxygen carrier can be then considered eligible for the next step in upscaling the CLC process.

However, it should be stressed that this methodology will be unable to totally ensure that the selected materials will have an ideal behaviour for use in a larger-scale CLC plant with regard to attrition because: (1) fluidization conditions in a large-scale CLC plant could be different to those existing in the smaller CLC pilot plant; and (2) the operating time in the CLC pilot plant is 
always limited, and there is no empirical evidence that oxygen carrier particles effectively will endure for their expected lifetime. It should be noted that during the experimental investigation, operating time is commonly lower than expected lifetime. Thus, this approach is proposed as a useful tool for screening out materials because it is able to predict which materials do not behave suitably in terms of attrition resistance. In this way, combining attrition values obtained during redox cycles at hot conditions in a CLC unit with AJI measurements can detect particles with a high likelihood of mechanical integrity failure, despite low attrition values obtained in the CLC unit. In these cases, the AJI measurements show monotonic increasing in the index value, and therefore it is not necessary to evaluate these particles for a long period of time in the continuous CLC pilot plant, with considerable savings in time and money.

Finally, this procedure to evaluate the attrition resistance of oxygen carriers could be improved by making it possible to study thermal, chemical and physical effects simultaneously during the AJI-ASTM tests. In order to achieve this objective, the attrition test assembly should be modified to include a furnace that can operate at typical CLC temperatures and a gas feeding system that allows cyclic reduction and oxidation tests to be carried out during attrition measurements.

\section{Conclusions}

The attrition behaviour of 23 oxygen carriers was evaluated through the analysis of several particle characteristics such as crushing strength, AJI according to ASTM D5757, and the attrition rate measured during multi-cycle redox reactions in a continuously operated CLC unit for gaseous fuels. Measuring the crushing strength and AJI for fresh oxygen carrier particles is not sufficient to predict the mechanical behaviour of materials in continuous CLC processes. In contrast, the AJI-ASTM test for particles subjected to long-term CLC operation can be used as a standard screening tool to foresee the attrition behaviour of oxygen carriers, in order to provide an indication of their potential use at an industrial scale. Furthermore, a methodology to select oxygen carriers as eligible materials for CLC scale-up regarding the attrition behaviour was proposed for the first time in the literature. 


\section{Acknowledgements}

The work presented in this article was partially funded by the Spanish Ministry of Economy and Competitiveness (ENE2013-45454-R), by the European Commission Seventh Framework Programme under grant agreement No. 608571 (Project acronym SUCCESS) and by the European Regional Development Fund (ERDF). A. Abad and A. Cabello thank CSIC for the financial support given to project 201480E101. ICB-CSIC also thanks Johnson Matthey for the preparation of some of the oxygen carriers tested in this work. 


\section{References}

[1] IPCC special report on carbon dioxide capture and storage, Cambridge University Press, Cambridge, UK, 2005.

[2] International Energy Agency, Energy policies review, The European Union, 2008.

[3] H.R. Kerr, Capture and separation technology gaps and priority research needs. Carbon dioxide capture for storage in deep geologic formations, in: D.C. Thomas, S.M. Benson, (Eds.), Results from the $\mathrm{CO}_{2}$ capture project, Elsevier, Oxford, 2005.

[4] J. Adánez, A. Abad, F. García-Labiano, P. Gayán, L.F. de Diego, Progress in Chemical Looping Combustion and Reforming Technologies, Prog. Energy Combust. Sci. 38 (2012) 215-82.

[5] A. Lyngfelt, Chemical-looping combustion of solid fuels - Status for development, Appl. Energy, 113 (2014) 1869-73.

[6] F. Scala, R. Chirone, P. Salatino, Attrition phenomena relevant to fluidized bed combustion and gasification systems, in: F. Scala (Ed.), Fluidized bed technologies for near-zero emission combustion and gasification, Woodhead Publishing Series in Energy, Cambridge, 2013, pp. 254-315.

[7] J. Werther, J. Reppenhagen, Attrition, in: W.C. Yang (Ed.), Handbook of fluidization and fluid particles system, Marcel Dekker, New York, 2003.

[8] M. Kramp, A. Thon, E.U. Hartge, S. Heinrich, J. Werther, The Role of Attrition and Solids Recovery in a Chemical Looping Combustion Process, Oil \& Gas Science and Technology - Rev. IFP Energies nouvelles 66 (2011) 277-90

[9] M. Rydén, P. Moldenhauer, S. Lindqvist, T. Mattisson, A. Lyngfelt, Measuring attrition resistance of oxygen carrier particles for chemical looping combustion with a customized jet cup, Powder Technol. 256 (2014) 75-86

[10] J. Adánez, C. Dueso, L.F. de Diego, F. García-Labiano, P. Gayán, A. Abad, Methane combustion in a $500 \mathrm{~W}_{\text {th }}$ chemical-looping combustion system using an impregnated Nibased oxygen carrier, Energy Fuels 23 (2009) 130-42. 
[11] C. Linderholm, T. Mattisson, A. Lyngfelt, Long-term integrity testing of spray-dried particles in a $10 \mathrm{~kW}$ chemical-looping combustor using natural gas as fuel, Fuel 88 (2009) 2083-96.

[12] C. Linderholm, A. Abad, T. Mattisson, A. Lyngfelt, $160 \mathrm{~h}$ of chemical-looping combustion in a $10 \mathrm{~kW}$ reactor system with a NiO-based oxygen carrier, Int. J. Greenhouse Gas Control (2008) 520-30.

[13] L.F. de Diego, F. García-Labiano, P. Gayán, J. Celaya, J.M. Palacios, J. Adánez, Operation of a $10 \mathrm{~kW}_{\text {th }}$ chemical-looping combustor during $200 \mathrm{~h}$ with a $\mathrm{CuO}-\mathrm{Al}_{2} \mathrm{O}_{3}$ oxygen carrier, Fuel 86 (2007) 1036-45.

[14] P. Gayán, M.A. Pans, M. Ortiz, A. Abad, L.F. de Diego, F. García-Labiano, Testing of a highly reactive impregnated $\mathrm{Fe}_{2} \mathrm{O}_{3} / \mathrm{Al}_{2} \mathrm{O}_{3}$ oxygen carrier for a SR-CLC system in a continuous CLC unit, Fuel Process. Technol. 96 (2012) 37-47.

[15] A. Lyngfelt, B. Kronberger, J. Adánez, J.X. Morin, P. Hurst, E.S. Rubin, D.W. Keith, C.F. Gilboy, M. Wilson, T. Morris, J. Gale, K. Thambimuthu, The GRACE project: Development of oxygen carrier particles for chemical-looping combustion. Design and operation of a $10 \mathrm{~kW}$ chemical-looping combustor, Int. J. Greenhouse Gas Control 7 (2005) 115-23.

[16] A. Abad, J. Adánez, F. García-Labiano, L.F. de Diego, P. Gayán, J. Celaya, Mapping of the range of operational conditions for $\mathrm{Cu}-, \mathrm{Fe}-$, and $\mathrm{Ni}$-based oxygen carriers in chemicallooping combustion, Chem. Eng. Sci. 62 (2007) 533-49.

[17] B. Amblard, S. Bertholin, C. Bobin, T. Gauthier, Development of an attrition evaluation method using a Jet Cup rig, Powder Technol. 274 (2015) 455-65.

[18] T.A. Brown, F. Scala, S.A. Scott, J.S. Dennis, P. Salatino, The attrition behaviour of oxygen-carriers under inert and reacting conditions, Chem. Eng. Sci. 71 (2012) 449-67.

[19] ASTM D5757-95: Standard Test Method for Determination of Attrition and Abrasion of Powdered Catalysts by Air Jets, ASTM, Philadelphia, 1995.

[20] A. Cabello, A. Abad, P. Gayán, L.F. de Diego, F. García-Labiano, J. Adánez, Effect of Operating Conditions and $\mathrm{H}_{2} \mathrm{~S}$ Presence on the Performance of $\mathrm{CaMg}_{0.1} \mathrm{Mn}_{0.9} \mathrm{O}_{3-\delta}$ 
Perovskite Material in Chemical Looping Combustion (CLC), Energy Fuels 28 (2014) $1262-74$.

[21] P. Gayán, A. Cabello, F. García-Labiano, A. Abad, L.F. de Diego, J. Adánez, Performance of a low Ni content oxygen carrier for fuel gas combustion in a continuous CLC unit using a $\mathrm{CaO} / \mathrm{Al}_{2} \mathrm{O}_{3}$ system as support, Int. J. Greenhouse Gas Control 14 (2013) 209-19.

[22] C.R. Forero, P. Gayán, F. García-Labiano, L.F. de Diego, A. Abad, J. Adánez, High temperature behaviour of a $\mathrm{CuO} / \gamma \mathrm{Al}_{2} \mathrm{O}_{3}$ oxygen carrier for chemical looping combustion, Int. J. Greenhouse Gas Control 5 (2011) 659-67.

[23] J. Adánez, P. Gayán, J. Celaya, L.F. de Diego, F. García-Labiano, A. Abad, Chemical Looping Combustion in a $10 \mathrm{~kW}$ th Prototype Using a $\mathrm{CuO} / \mathrm{Al}_{2} \mathrm{O}_{3}$ Oxygen Carrier: Effect of Operating Conditions on Methane Combustion, Ind. Eng. Chem. Res. 45 (2006) 607580.

[24] P. Gayán, A. Cabello, A. Abad, F. García-Labiano, L. F. de Diego, J. Adánez, Development of impregnated oxygen carriers at industrial scale for $\mathrm{CH}_{4}$ combustion in a Chemical Looping Combustion process, Proc. Brussels Sustainable Development Submit, Brussels, Belgium, 2015.

[25] P. Gayán, C.R. Forero, A. Abad, L.F. de Diego, F. García-Labiano, J. Adánez, Effect of support on the behaviour of $\mathrm{Cu}$-based oxygen carriers during long-term CLC operation at temperatures above 1073 K, Energy Fuels 25 (2011) 1316-26.

[26] J. Adánez, Long term operation of new oxygen carriers with no Ni content during gas combustion in CLC, Proc. CCS Conference 2013, Antwerp, Belgium, 2013.

[27] A. Cabello, C. Dueso, F. García-Labiano, P. Gayán, A. Abad, L.F. de Diego, J. Adánez, Performance of a highly reactive impregnated $\mathrm{Fe}_{2} \mathrm{O}_{3} / \mathrm{Al}_{2} \mathrm{O}_{3}$ oxygen carrier with $\mathrm{CH}_{4}$ and $\mathrm{H}_{2} \mathrm{~S}$ in a $500 \mathrm{~W}_{\text {th }}$ CLC unit, Fuel 121 (2014) 117-25.

[28] M.A. Pans, P. Gayán, L.F. de Diego, F. García-Labiano, A. Abad, J. Adánez, Performance of a low-cost iron ore as an oxygen carrier for Chemical Looping Combustion of gaseous fuels, Chem. Eng. Res. Des. 93 (2015) 736-46. 
[29] M. Johansson, T. Mattisson, A. Lyngfelt, Investigation of $\mathrm{Fe}_{2} \mathrm{O}_{3}$ with $\mathrm{MgAl}_{2} \mathrm{O}_{4}$ for chemical-looping combustion, Ind. Eng. Chem. Res. 43 (2004) 6978-87.

[30] R.P. Gupta, B.S. Turk, A.A. Vierheilig, Desulfurization Sorbents for Transport-Bed Applications, Proceedings of the Advanced Coal-Based and Environmental Systems Pittsburgh, 1997. 


\section{Figure Captions}

Figure 1. Schematic diagram of the $500 \mathrm{~W}_{\text {th }}$ continuous CLC system (ICB-CSIC-g1 facility).

Figure 2. Attrition rate profile of the $\mathrm{Cu}_{-} 4$ oxygen carrier tested in the $500 \mathrm{~W}_{\text {th }}$ continuous CLC system.

Figure 3. Comparison between crushing strength and Air Jet Index (AJI) for fresh oxygen carrier particles.

Figure 4. Particle lifetime estimated in the $500 \mathrm{~W}_{\text {th }}$ continuous CLC system versus crushing strength values of fresh oxygen carrier particles.

Figure 5. Particle lifetime estimated in the $500 \mathrm{~W}_{\text {th }}$ continuous CLC system versus Air Jet Index (AJI) values of fresh oxygen carrier particles.

Figure 6. Evolution of the (a) Air Jet Index (AJI) and (b) attrition rate throughout the time of operation in the $500 \mathrm{~W}_{\text {th }}$ continuous $\mathrm{CLC}$ system for the $\mathrm{Fe} \_6, \mathrm{Cu} \_4 \mathrm{a}$ and $\mathrm{Cu} \_4 \mathrm{~b}$ oxygen carriers.

Figure 7. Air Jet Index (AJI) for particles before and after an experimental campaign.

Figure 8. Particle size distribution (PSD) profiles of (a) Fe_3, (b) Fe_6, and Ni_1 (c) oxygen carriers.

Figure 9. Particle lifetime estimated in the $500 \mathrm{~W}_{\text {th }}$ continuous CLC system versus Air Jet Index (AJI) values of used oxygen carrier particles.

Figure 10. Proposed methodology to select oxygen carriers as eligible materials for CLC scaleup with regard to attrition behaviour. 


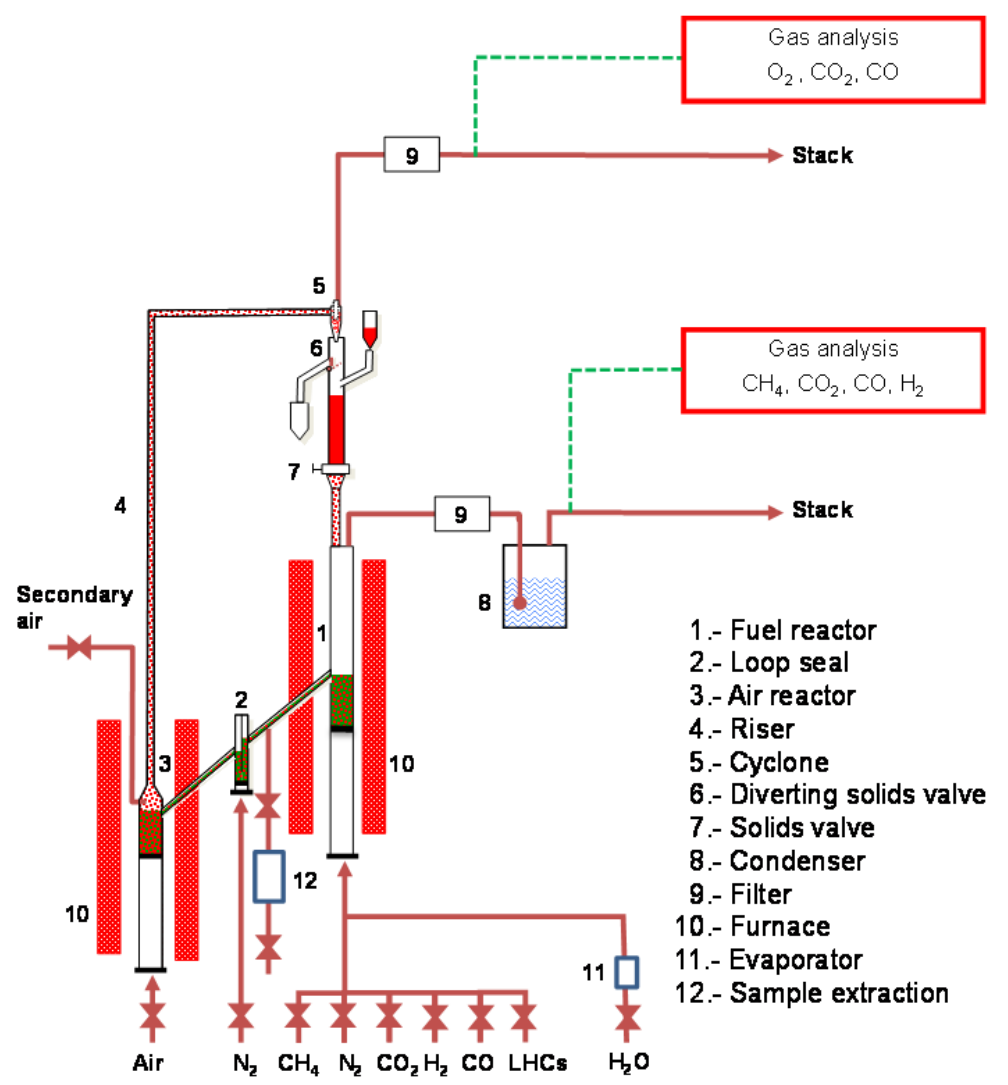

Figure 1. Schematic diagram of the $500 \mathrm{~W}_{\text {th }}$ continuous CLC system (ICB-CSIC-g1 facility). 


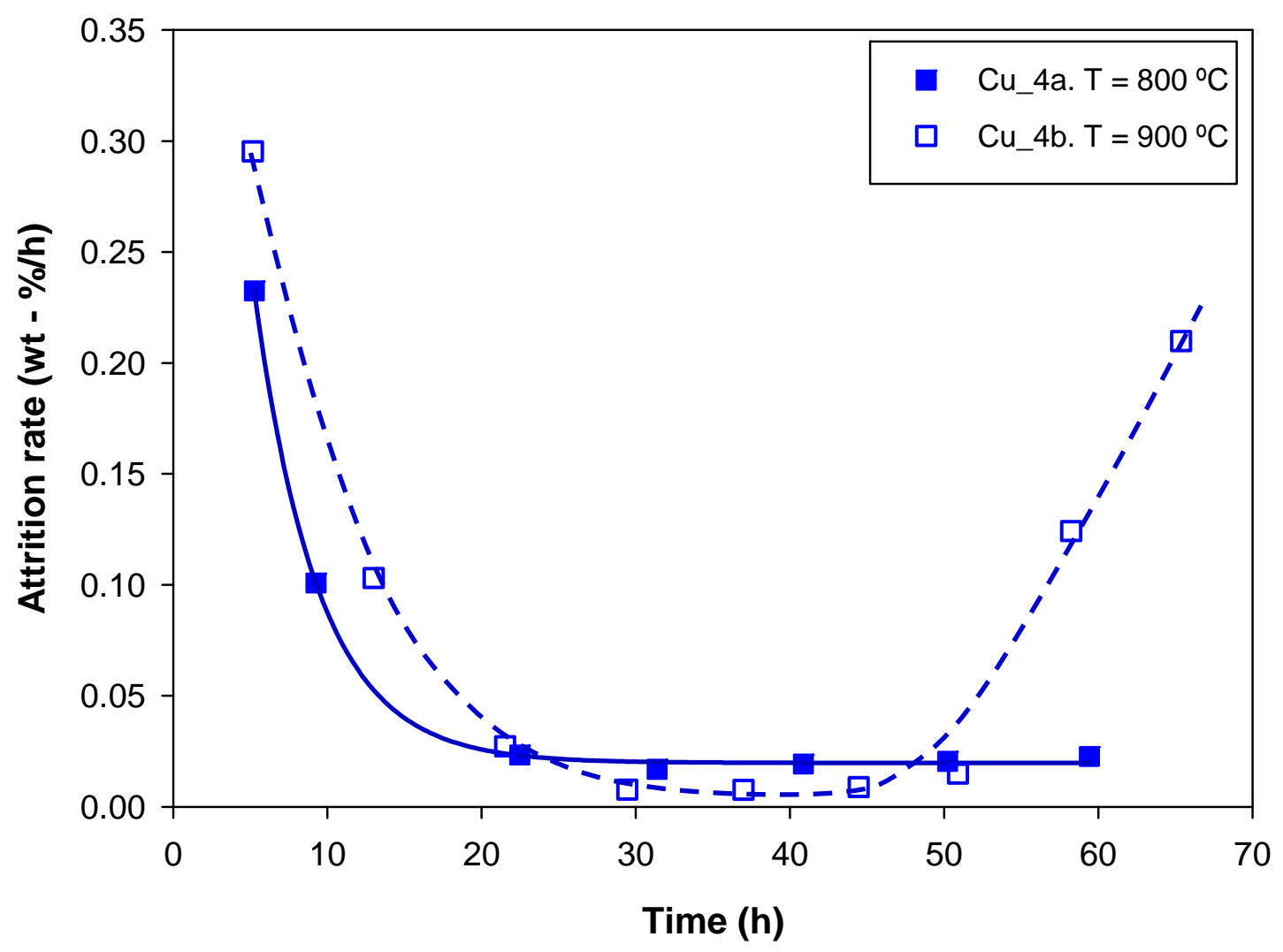

Figure 2. Attrition rate profile of the $\mathrm{Cu}_{-} 4$ oxygen carrier tested in the $500 \mathrm{~W}_{\text {th }}$ continuous CLC system. 


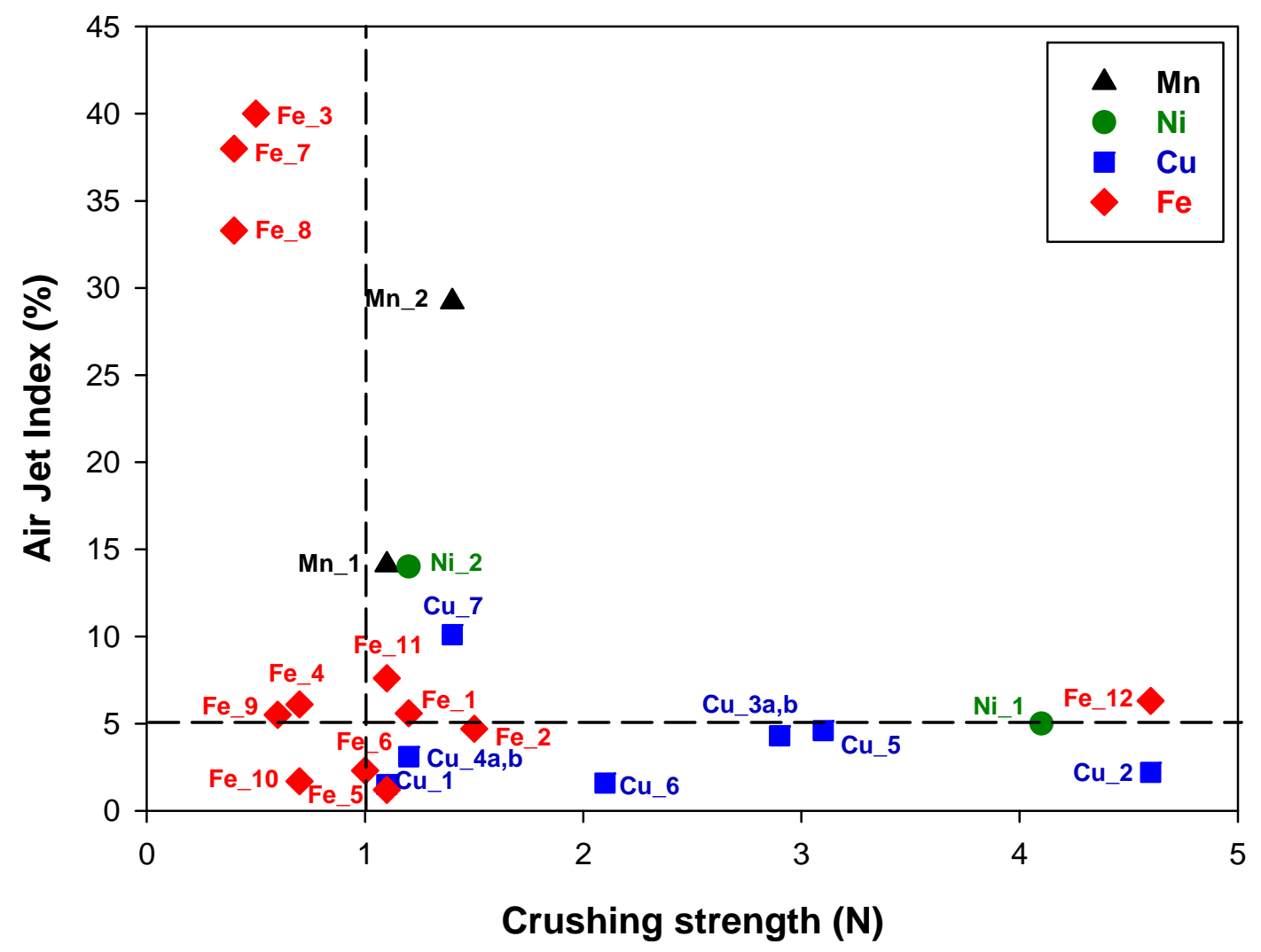

Figure 3. Comparison between crushing strength and Air Jet Index (AJI) for fresh oxygen carrier particles. 


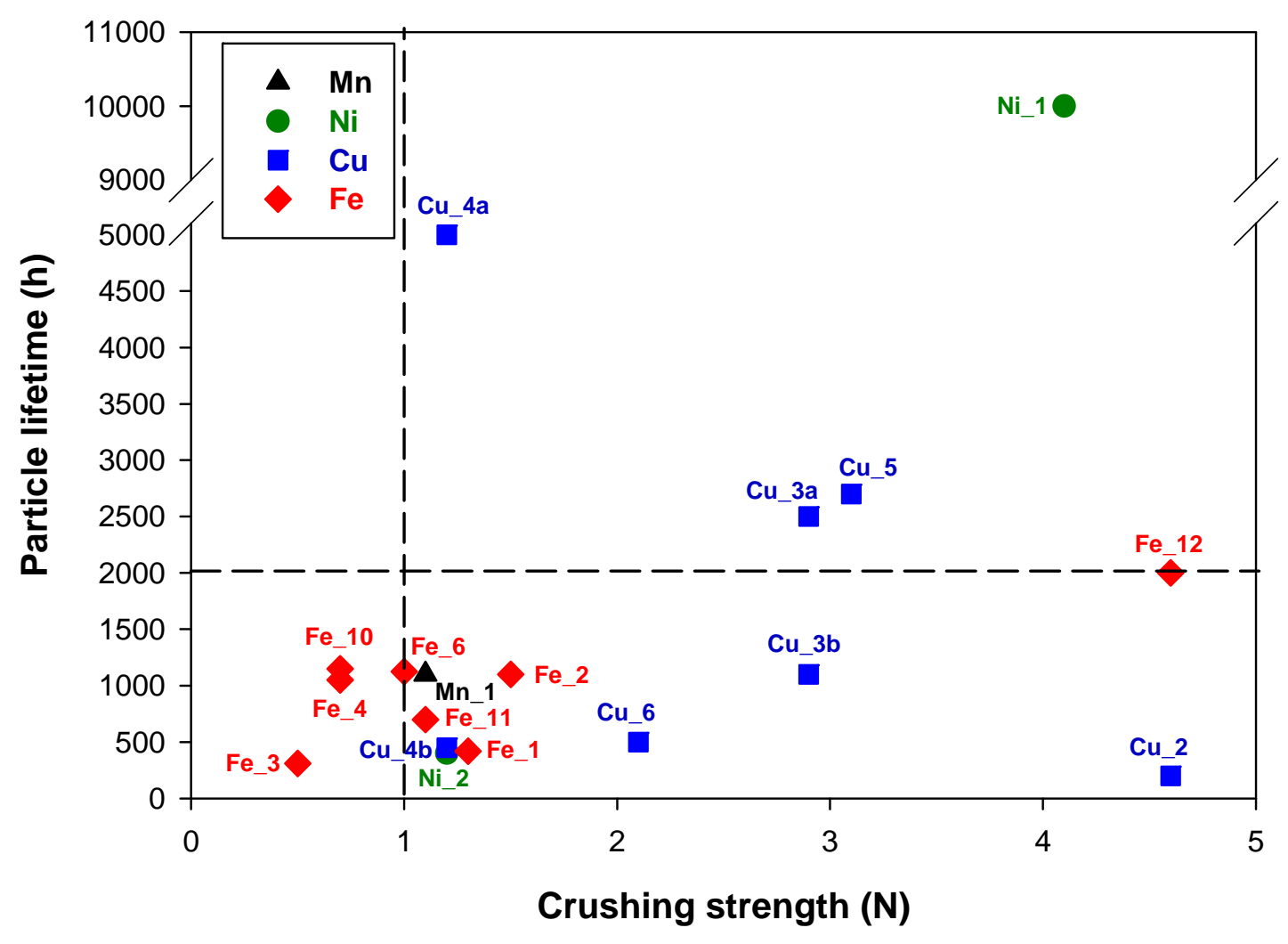

Figure 4. Particle lifetime estimated in the $500 \mathrm{~W}_{\text {th }}$ continuous CLC system versus crushing strength values of fresh oxygen carrier particles. 


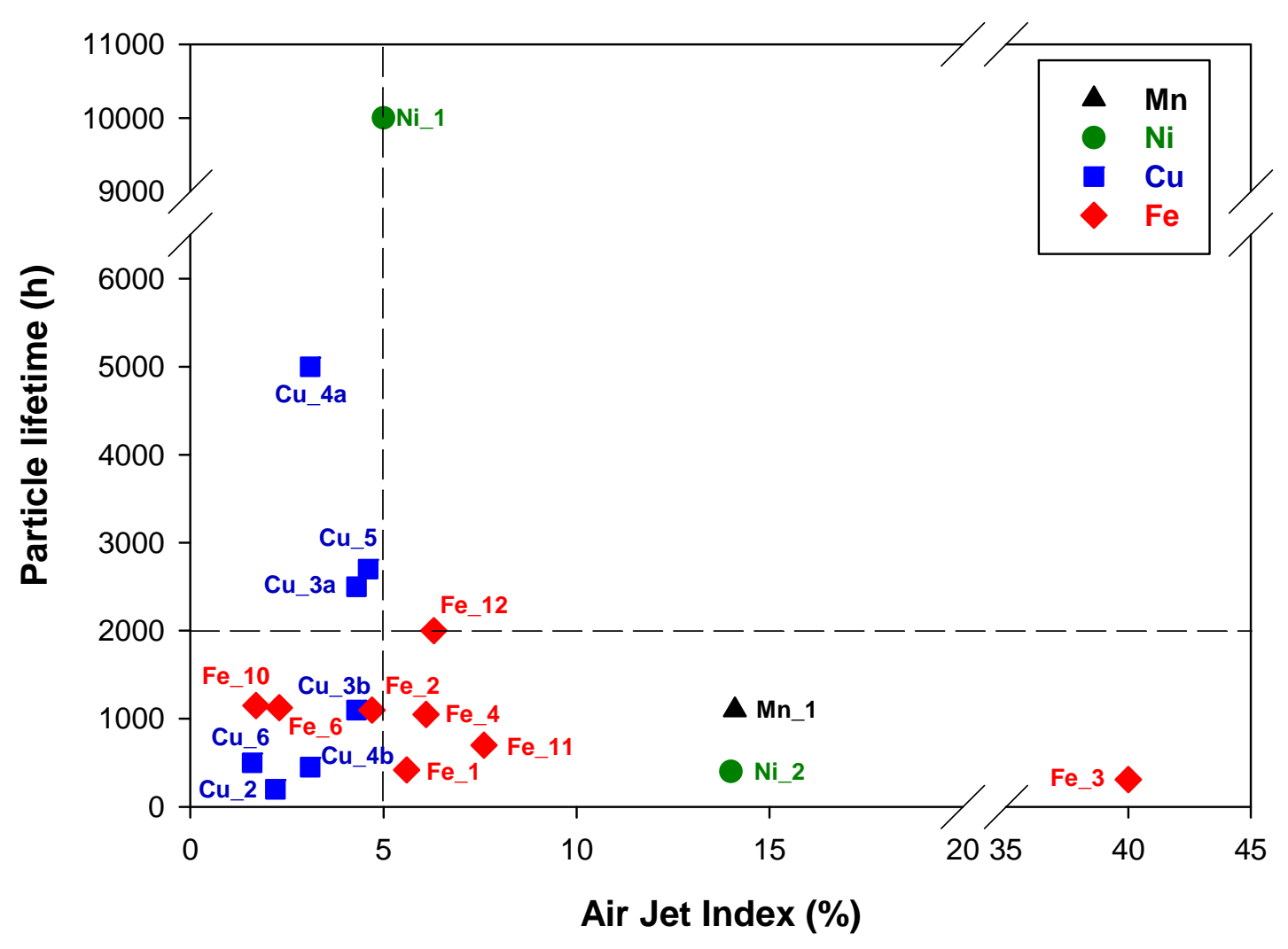

Figure 5. Particle lifetime estimated in the $500 \mathrm{~W}_{\text {th }}$ continuous CLC system versus Air Jet Index (AJI) values of fresh oxygen carrier particles. 

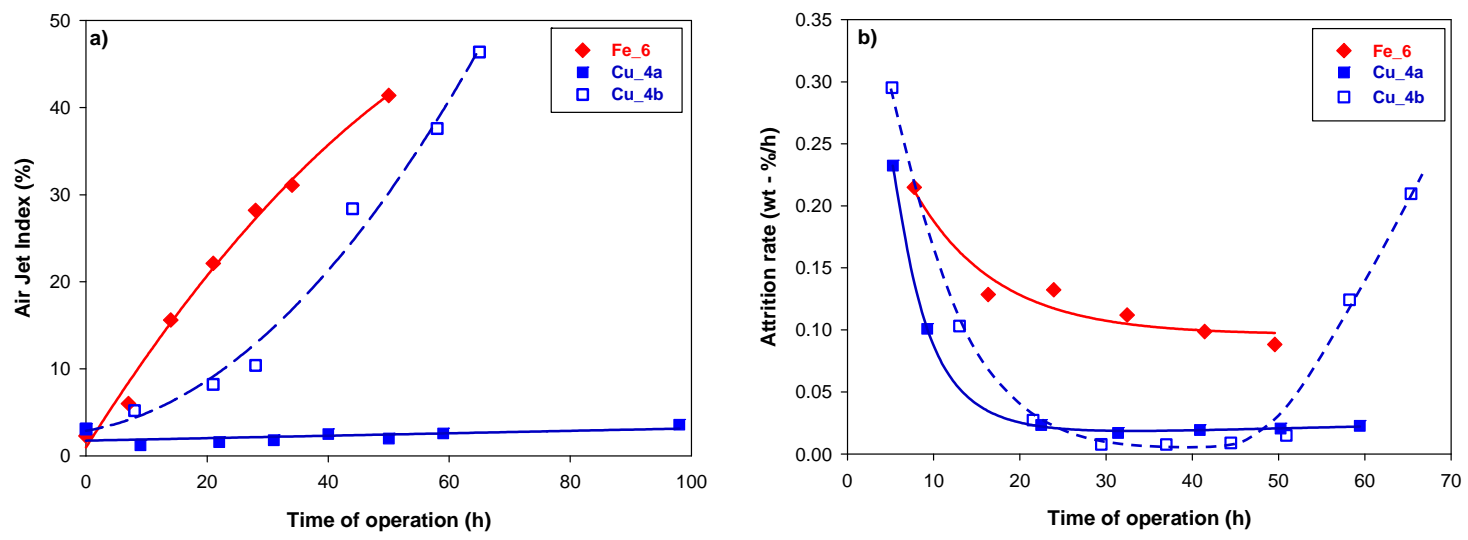

Figure 6. Evolution of the (a) Air Jet Index (AJI) and (b) attrition rate throughout the time of operation in the $500 \mathrm{~W}_{\text {th }}$ continuous $\mathrm{CLC}$ system for the $\mathrm{Fe} \_6, \mathrm{Cu}_{-} 4 \mathrm{a}$ and $\mathrm{Cu}_{-} 4 \mathrm{~b}$ oxygen carriers. 


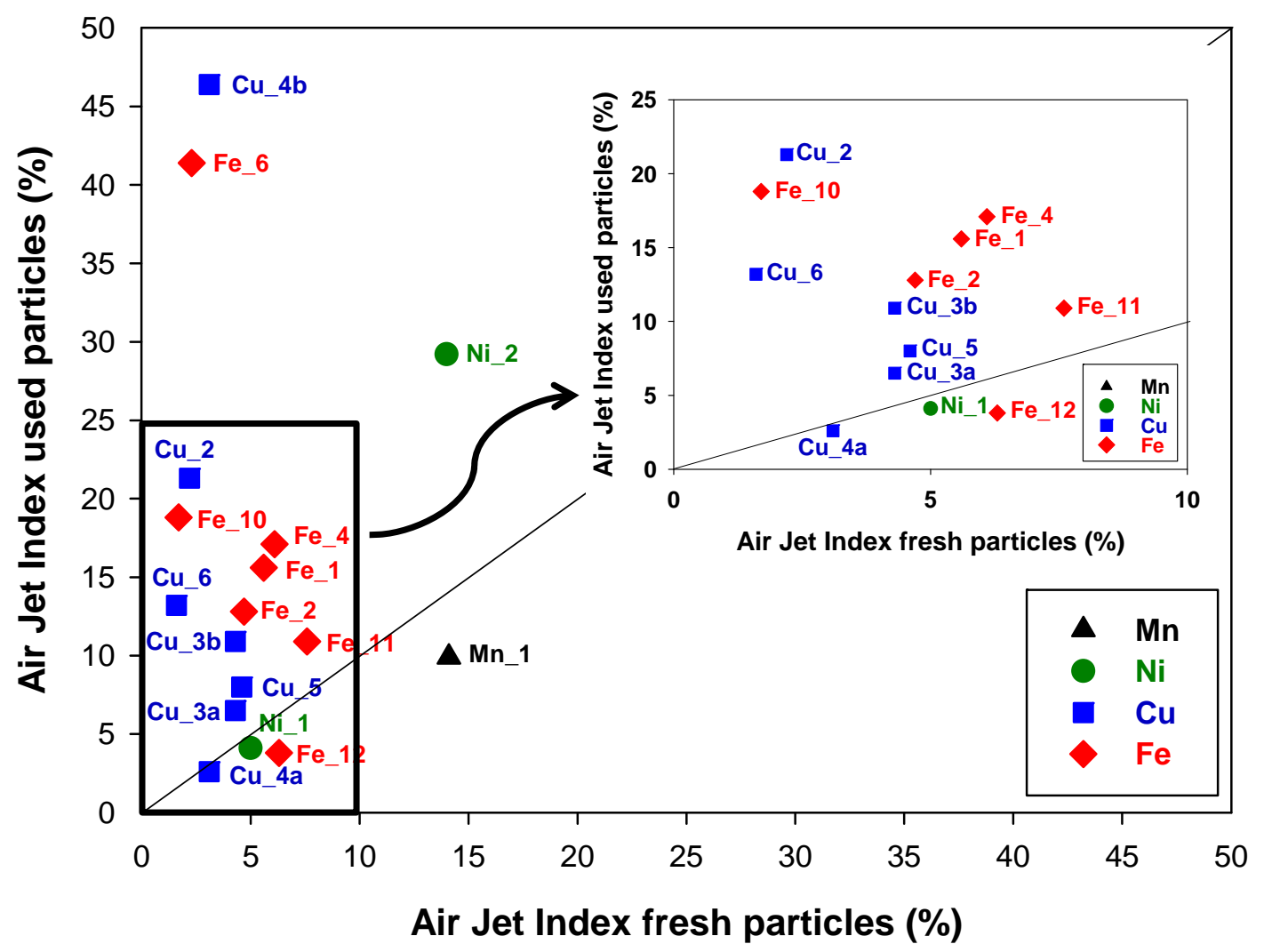

Figure 7. Air Jet Index (AJI) for particles before and after an experimental campaign. 

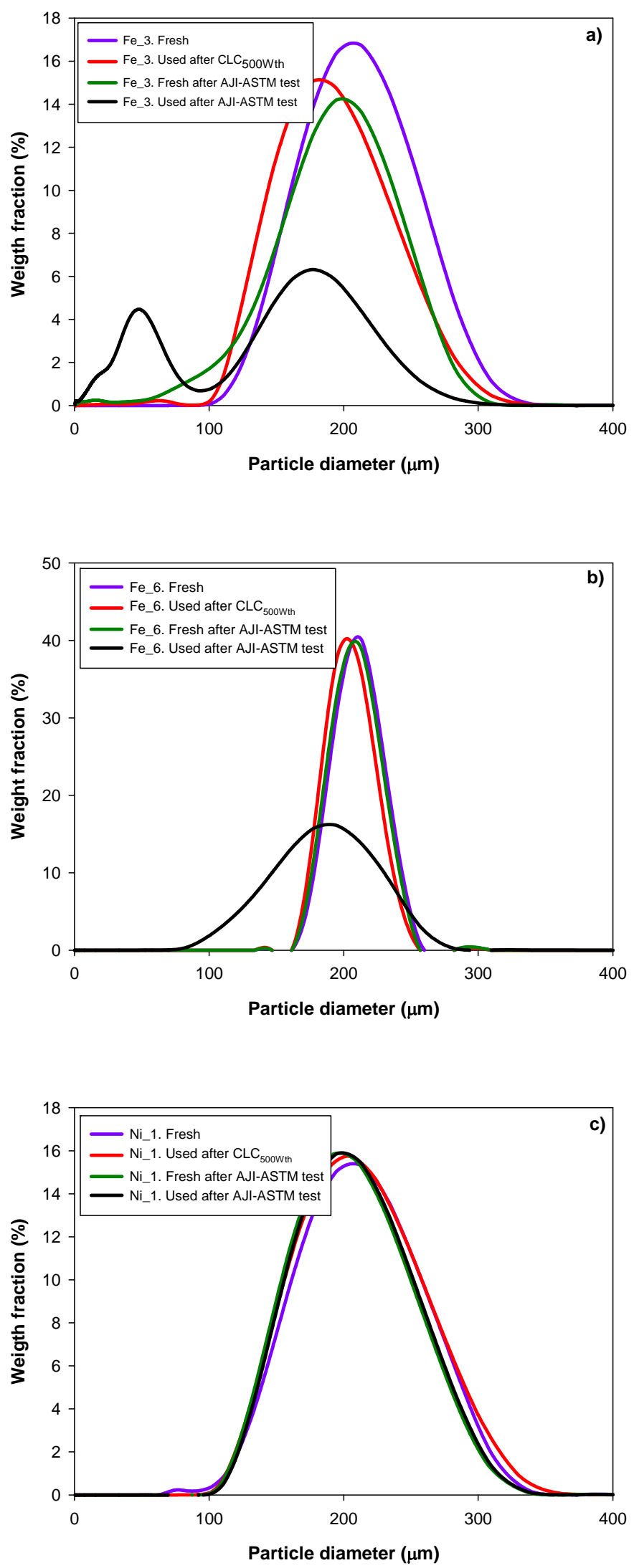

Figure 8. Particle size distribution (PSD) profiles of (a) $\mathrm{Fe} \_3$, (b) $\mathrm{Fe} \_6$, and $\mathrm{Ni}_{-} 1$ (c) oxygen carriers. 


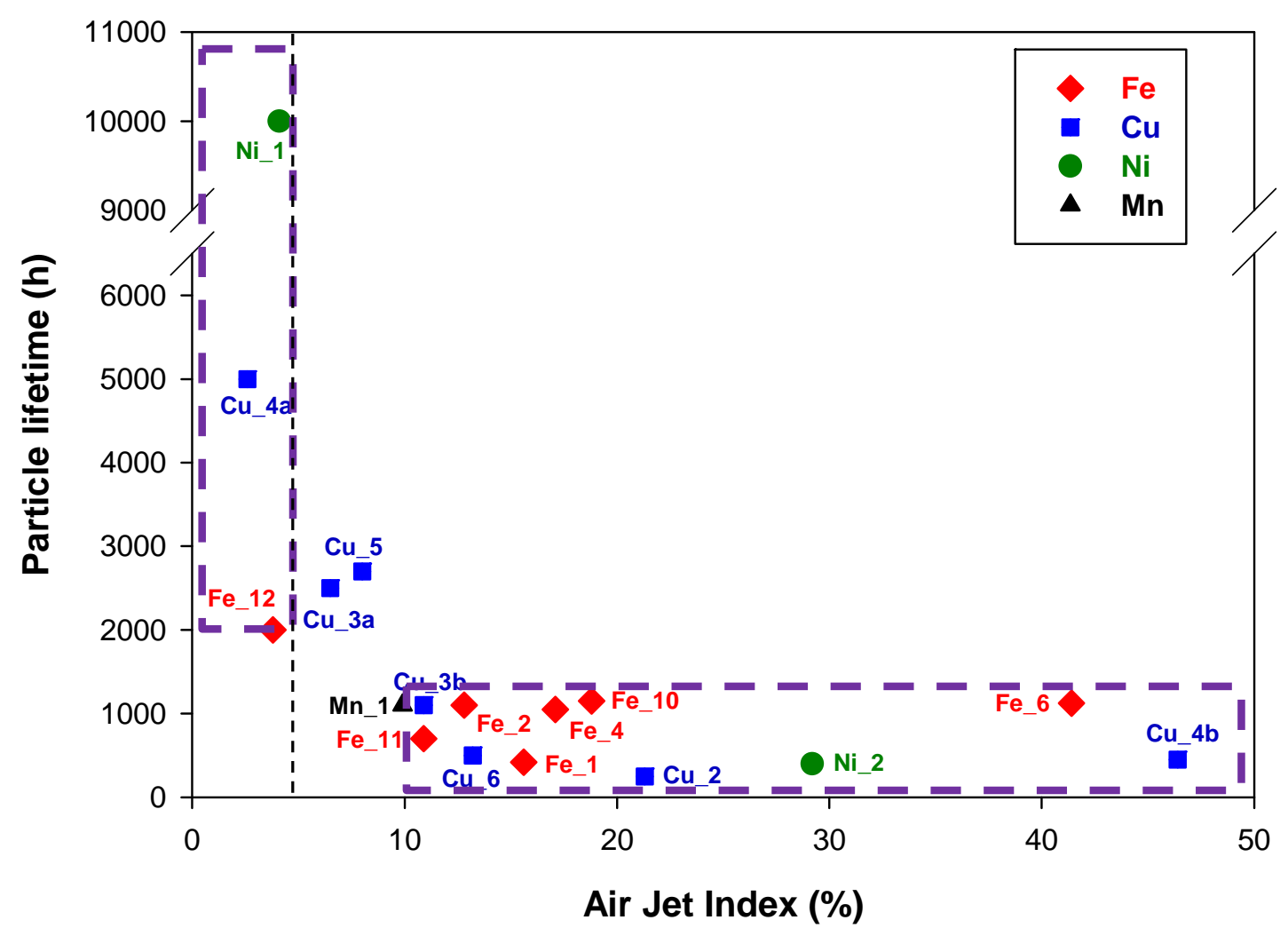

Figure 9. Particle lifetime estimated in the $500 \mathrm{~W}_{\text {th }}$ continuous CLC system versus Air Jet Index (AJI) values of used oxygen carrier particles. 


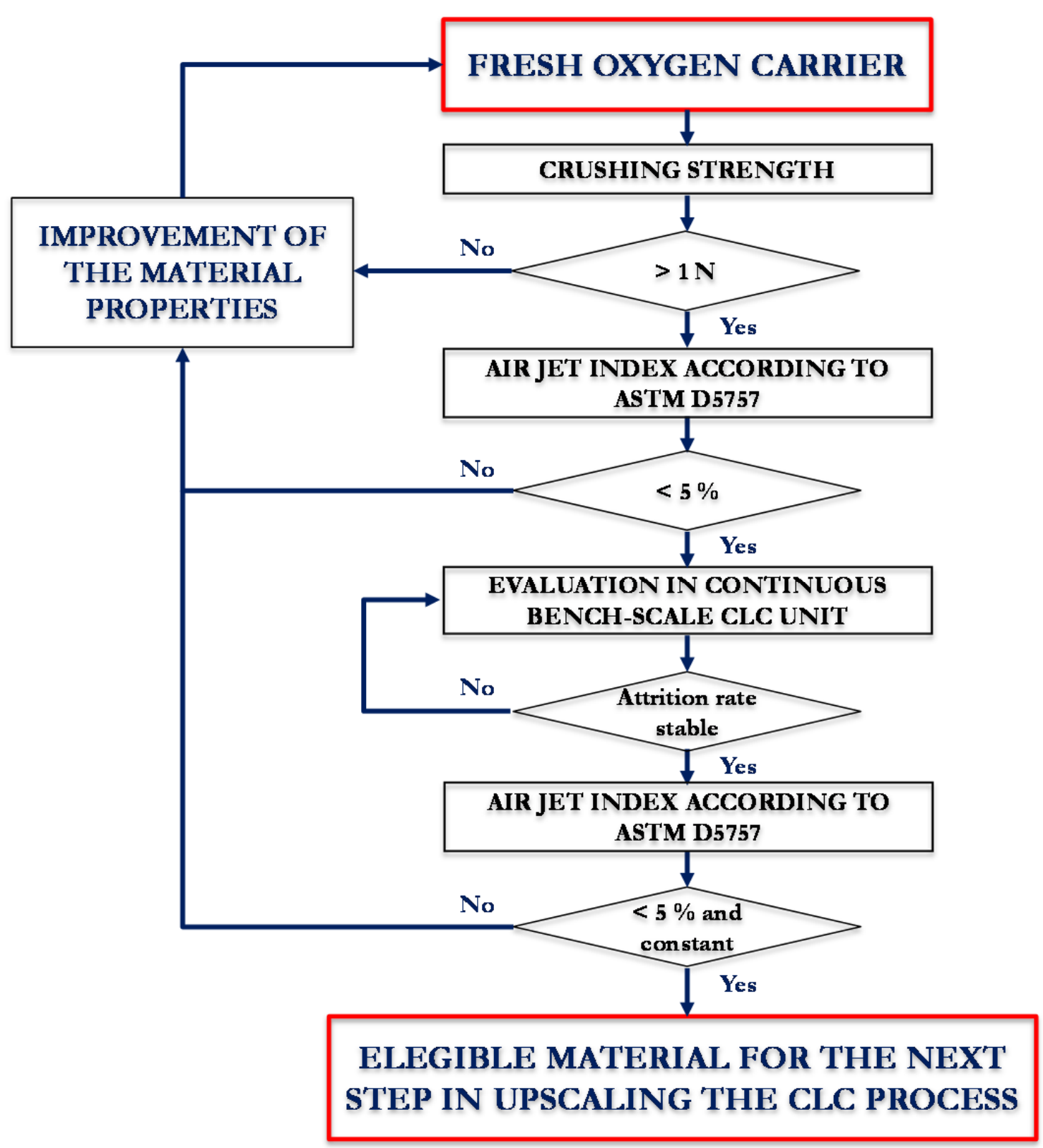

Figure 10. Proposed methodology to select oxygen carriers as eligible materials for CLC scaleup with regard to attrition behaviour. 


\section{Tables}

Table 1. Summary of the main operating conditions used during the tests performed in the continuous CLC unit.

Table 2. Summary of the results obtained in this work. 
Table 1. Summary of the main operating conditions used during the tests performed in the continuous CLC unit.

\begin{tabular}{|l|c|c|}
\hline Parameter & Units & Values \\
\hline Fuel reactor temperature & $\left({ }^{\circ} \mathrm{C}\right)$ & $800-900$ \\
\hline Air reactor temperature & $\left({ }^{\circ} \mathrm{C}\right)$ & $800-950$ \\
\hline Total solids inventory & $(\mathrm{kg})$ & $1.0-1.7$ \\
\hline Solids circulation rate & $\left(\mathrm{kg} / \mathrm{m}^{2} \mathrm{~s}\right)$ & $3.5-17.7$ \\
\hline Gas velocity at the fuel reactor inlet & $(\mathrm{m} / \mathrm{s})$ & $0.1-0.15$ \\
\hline Gas velocity at the air reactor inlet & $(\mathrm{m} / \mathrm{s})$ & $0.4-0.45$ \\
\hline Gas velocity in the riser & $(\mathrm{m} / \mathrm{s})$ & $3.0-3.4$ \\
\hline
\end{tabular}


Table 2. Summary of the results obtained in this work.

\begin{tabular}{|c|c|c|c|c|c|c|c|c|c|c|c|c|c|}
\hline \multicolumn{4}{|c|}{ Oxygen-carrier } & \multicolumn{2}{|c|}{ Fresh } & \multicolumn{5}{|c|}{ CLC unit } & \multicolumn{2}{|c|}{ Used } & \multirow[t]{2}{*}{$\overline{\text { Citation }}$} \\
\hline Reference & $\begin{array}{c}\text { Active metal } \\
\text { oxide content } \\
\text { (wt. \%) }\end{array}$ & Support $^{1}$ & $\begin{array}{c}\text { Method of } \\
\text { preparation }^{2}\end{array}$ & $\begin{array}{l}\text { Crushing } \\
\text { strength } \\
(\mathrm{N}) \\
\end{array}$ & $\begin{array}{l}\text { AJI } \\
(\%) \\
\end{array}$ & $\begin{array}{c}\text { Operation } \\
\text { time } \\
\text { (h) }\end{array}$ & Fuel $^{3}$ & $\begin{array}{l}\mathrm{T}_{\mathrm{FR}} \\
\left({ }^{\circ} \mathrm{C}\right) \\
\end{array}$ & $\begin{array}{l}\text { Attrition } \\
\text { rate } \\
(\% / h) \\
\end{array}$ & $\begin{array}{c}\text { Particle } \\
\text { lifetime } \\
\text { (h) }\end{array}$ & $\begin{array}{l}\text { Crushing } \\
\text { strength } \\
(\mathrm{N}) \\
\end{array}$ & $\begin{array}{l}\text { AJI } \\
(\%) \\
\end{array}$ & \\
\hline Mn_1 & $\mathrm{CaMn}_{0.9} \mathrm{Mg}_{0.1} \mathrm{O}_{3 \delta}$ & --- & SD & 1.1 & 14.1 & 71 & $\mathrm{CH}_{4}$ & 900 & 0.03 & 1100 & 1.2 & 9.9 & {$[20]$} \\
\hline Mn_2 & $\begin{array}{c}\mathrm{CaMn}_{0.875} \mathrm{Ti}_{0.125} \\
\mathrm{O}_{3 \delta}\end{array}$ & --- & $\mathrm{SD}$ & 1.4 & 29.2 & --- & --- & & --- & --- & --- & --- & \\
\hline Ni_1 & 18 & Al_1 & I & 4.1 & 5.0 & 100 & $\mathrm{CH}_{4}$ & $800-880$ & 0.01 & 10000 & 3.7 & 4.1 & {$[10]$} \\
\hline $\mathrm{Ni}$ & 11 & $\mathrm{CaA} \mathrm{Al}$ & I & 1.2 & 14 & 90 & $\mathrm{CH}_{4}$, syngas, LHCs & 900 & 0.25 & 400 & 0.6 & 29.2 & [21] \\
\hline $\mathrm{Cu} \_1$ & 16 & Al_2 & I & 1.1 & 1.5 & --- & -- & --- & --- & --- & --- & --- & \\
\hline $\mathrm{Cu}^{-} 2$ & 15 & $\mathrm{Al}^{-} 1$ & I & 4.6 & 2.2 & 30 & $\mathrm{CH}_{4}$ & 900 & $>0.4$ & $<250$ & 1.8 & 21.3 & [22] \\
\hline $\mathrm{Cu}_{-}{ }^{-} 3 \mathrm{a}$ & 14 & Al_3 & I & 2.9 & 4.3 & 100 & $\mathrm{CH}_{4}$ & 800 & 0.04 & 2500 & --- & 6.5 & [23] \\
\hline $\mathrm{Cu}_{-}{ }^{-} 3 \mathrm{~b}$ & 14 & $\mathrm{Al} \_3$ & I & 2.9 & 4.3 & 63 & $\mathrm{CH}_{4}$ & 900 & 0.09 & 1100 & 0.6 & 10.9 & [22] \\
\hline $\mathrm{Cu}_{-} 4 \mathrm{a}$ & 14 & $\mathrm{Al}_{-} 4$ & I & 1.2 & 3.1 & 59 & $\mathrm{CH}_{4}$ & 800 & 0.02 & 5000 & 1.2 & 2.6 & [24] \\
\hline $\mathrm{Cu}^{-} 4 \mathrm{~b}$ & 14 & $\mathrm{Al}^{-} 4$ & I & 1.2 & 3.1 & 65 & $\mathrm{CH}_{4}$ & 900 & $>0.22$ & $<450$ & 0.7 & 46.4 & \\
\hline $\mathrm{Cu}^{-} 5$ & 12.8 & $\mathrm{NiA} \mathrm{Al}$ & I & 3.1 & 4.6 & 67 & $\mathrm{CH}_{4}$ & 900 & 0.04 & 2700 & 2.0 & 8.0 & [25] \\
\hline $\mathrm{Cu}_{-}^{-} 6$ & 12 & $\mathrm{MgAl}$ & I & 2.1 & 1.6 & 50 & $\mathrm{CH}_{4}$ & 900 & 0.20 & 500 & 1.7 & 13.2 & {$[25]$} \\
\hline $\mathrm{Cu}^{-} 7$ & 14 & $\mathrm{Zr}$ & $\mathrm{I}$ & 1.4 & 10.1 & --- & --- & --- & --- & --- & --- & --- & \\
\hline $\mathrm{Fe} \_1$ & 24 & Al_5 & I & 1.3 & 5.6 & 51 & $\mathrm{CH}_{4}$ & 900 & 0.25 & 420 & 0.6 & 15.6 & [26] \\
\hline $\mathrm{Fe}_{-}-2$ & 20 & $\mathrm{Al}^{-} 3$ & I & 1.5 & 4.7 & 75 & $\mathrm{CH}_{4}$ & 880 & 0.09 & 1100 & 0.9 & 12.8 & [27] \\
\hline $\mathrm{Fe}_{-3}^{-3}$ & 20 & Al_6 & I & 0.5 & 40.0 & 52 & $\mathrm{CH}_{4}$ & 900 & 0.32 & 310 & 0.3 & 79.3 & [24] \\
\hline $\mathrm{Fe}_{-}^{-} 4$ & 20 & $\mathrm{Al}_{-} 4$ & $\mathrm{I}$ & 0.7 & 6.1 & 50 & $\mathrm{CH}_{4}$ & 900 & 0.09 & 1050 & 0.8 & 17.1 & [24] \\
\hline $\mathrm{Fe}^{-} 5$ & 20 & $\mathrm{Al}_{-} 4$ & Ia & 1.1 & 1.2 & --- & --- & --- & --- & --- & --- & --- & \\
\hline $\mathrm{Fe}^{-} 6$ & 20 & $\mathrm{Al}^{-} 7$ & I & 1.0 & 2.3 & 52 & $\mathrm{CH}_{4}$ & 900 & 0.09 & 1125 & 1.0 & 41.4 & {$[24]$} \\
\hline $\mathrm{Fe}_{-} 7$ & 20 & Al_8 & I & 0.4 & 38.0 & --- & --- & --- & --- & --- & --- & --- & \\
\hline $\mathrm{Fe}-8$ & 20 & Al_9 & I & 0.4 & 33.3 & --- & --- & --- & --- & --- & --- & --- & \\
\hline $\mathrm{Fe}^{-} 9$ & 20 & $\mathrm{Al} \_\overline{1} 0$ & I & 0.6 & 5.5 & --- & --- & --- & --- & --- & --- & --- & \\
\hline $\mathrm{Fe} \_10$ & 18 & Al_2 & I & 0.7 & 1.7 & 77 & $\mathrm{CH}_{4}$ & 900 & 0.09 & 1150 & 0.5 & 18.8 & {$[24]$} \\
\hline $\mathrm{Fe}^{-} 11$ & 17 & $\mathrm{Al}^{-} 3$ & I & 1.1 & 7.6 & 19 & $\mathrm{CH}_{4}$ & 900 & 0.14 & 700 & 1.5 & 10.9 & \\
\hline $\mathrm{Fe}^{-} 12$ & 76 & -- & Iron ore & 4.6 & 6.3 & 50 & $\mathrm{CH}_{4}$, PSA-off gas & $830-930$ & 0.05 & 2000 & 3.0 & 3.8 & [28] \\
\hline
\end{tabular}


